\title{
Research on the FDI Inflows in Western Region of China - Exemplified by Guangxi Zhuang Autonomous Region
}

\author{
Lina $\operatorname{Lian}^{1}$ \\ ${ }^{1}$ School of Economics, Northwest University for Nationalities, Lanzhou, China \\ Correspondence: Lina Lian, Associate Professor, School of Economics, Northwest University for Nationalities, \\ Lanzhou 730124, China. E-mail: 1lnhappy2010@126.com
}

Received: December 14, 2012

Accepted: January 15, 2013

Online Published: April 8, 2013

doi:10.5430/ijfr.v4n2p42

URL: http://dx.doi.org/10.5430/ijfr.v4n2p42

This work was supported by the Fundamental Research Funds for the Central Universities of Northwest University for Nationalities China under grants ZYZ2012010.

\begin{abstract}
Since China gained the membership into WTO, the huge market potentiality and the improved investment environment combined together contributed significantly to the economic development of China. Yet FDI (Foreign Direct Investment) is not allotted equally in different regions of China. Compared with the inward FDI in the eastern and mid regions of China, the western region has attracted less FDI. FDI is fuelling much of the rapid economic leap of the developed regions of China and the significant inequity grow further, for the reason that these inflows of investment in western regions are, however, limited in the total volume and concentrated both by country of origin, industries and regions. Taking Guangxi Zhuang Autonomous Region as an example, the author concludes that the FDI policies of western region are no longer producing optimal results. The government should formulate corresponding measures to attract FDI inflows, meanwhile adjust the regional structure of FDI so as to further spur the economy development.
\end{abstract}

Keywords: FDI inflow, western region, economy development

\section{Introduction}

It is of little doubt that FDI (Foreign Direct Investment) has contributed significantly to Chinese economic development, and much and perhaps most of the growth of China's exports can be attributed to foreign-invested enterprises. The per capita income growth in those coastal regions of China where FDI is concentrated has been demonstrably higher than that of other regions. The sector and geographic distribution of the FDI is quite uneven. The majority of FDI in China is located in coastal provinces with Guangdong, Jiangsu, Fujian and Shanghai in descending order, and the residual majority even immediately adjacent to the coastal areas is slightly touched. By the end of year 2010, the foreign-sponsored enterprises in China climbed up to the total of 710,641, and the actual utilized FDI amounted to US $\$ 1051.2$. The eastern regions took up the proportion of $83.3 \%$ and 86.5 respectively, and the mid-regions $10.7 \%$ and $8.1 \%$. With 12 provinces and cities as Chongqing, Sichuan, Guizhou, Yunnan, Tibet, Shanxi, Gansu, Qinghai, Xinjiang, Ningxia, Guangxi and Inner Mongolia, the western regions only covered 6\% and $5.4 \%$ respectively. In the total western FDI inflows of 2010, Sichuan topped the list of all the western provinces and took the proportion of $37.4 \%$, followed by Chongqing $29.1 \%$, Shanxi $10.1 \%$, and Guangxi $8.4 \%$. Located in the south-west of the coastal areas of China, adjacent to Vietnam, Guangxi Zhuang Autonomous Region occupies large areas both inland and marine, around $2.46 \%$ of the total areas of China. Guangxi is world renowned for its scenic spots and historic culture, well- endowed with many natural resources, and most importantly, it is the usual and appropriate route of the business connections between China and 10 ASEAN countries. Yet the story of FDI in Guangxi is not quite as rosy as what should be expected.

Furthermore, FDI inflows of Guangxi Zhuang Autonomous Region is largely engaged in export-intensive manufacturing by performing labor-intensive operations on imported goods for re-export as OEM alleged loudly, thus it is not well integrated into mainstream of Chinese economy. The second FDI surge in the top 10 is non-traded commercial real estate development which has not been driven by positive changes in China rather than for profit 
dynamics.

Based on the statistical data of various sources, this study portrays the inward FDI flows of Guangxi Zhuang Autonomous Region from the perspectives of poor FDI volume, over-concentration of FDI affiliates, the lack of industries zoning and funding sectors, the mal-allotment of recipient regions, the non-diversified modes of FDI inflows etc. The first section of the study encompasses an introduction to the FDI inflows in Guangxi Zhuang Autonomous Region of China. Section Two outlines the core conclusions of the researchers and practitioners about the issue in question. Section Three portrays the FDI cohesions as exemplified by the affirmative data. Section Four sketches some reflections about the concrete actions to further the FDI attraction yet tailed to the local economy development agenda.

\section{Literature Review}

A large number of literatures have empirically studied the FDI location choice in China. The idea of FDI agglomeration in certain regions or places can be traced back to as far as Marshall (1920), who pointed out the reasons of agglomeration are that firms pursuit internal and external economies of scale. The key interests resulted from agglomeration are specialized labor market, a stable supply of intermediate inputs and demand for final products and technology spillovers. Redding and Venables (2004) pointed out that the geographic location, thus the degree of openness will affect the flows of goods, factors and information, and will naturally affect the location choice of FDI. Wang and Xu (2005) used the data sample of foreign-funded enterprises in Jiangsu province and found these industries showed some degrees of heterogeneity in attracting FDI that more specialized industries tend to have more FDI agglomerated, because more industrialized industries are usually inclined to have a longer value-added chain. Zhang and Chen (2006), in their papers, concluded that the rise in percentage of foreign-funded enterprises output in one province can increase the probability of FDI inflow in that region. Du et al. (2008) analyzed the location perspectives of US multinational corporations in 1993-2001 in China, and found that US multinationals tend to invest in places where they have efficient intellectual property protection, low government intervention in commercial transactions, scarce government corruption and better contract execution.

Many scholars are trying to portray the internal reasons of differentiated inward FDI flows in different regions of China. Zhang and $\mathrm{Wu}(2005)$ in their essay concluded that temporary demand had speeded up FDI inflows, yet the spillover effects of FDI did not exercise well in the western regions of China. Based on the data from 1985 to 2006, Gao Yanting (2008) proved the differentiated spur of FDI to the economic development of eastern and western regions China. Cui and Li (2010) focused on the contribution rate of FDI injection to GDP growth of the three regions of China. Dou Dengquan (2011) concluded that the influences of FDI on the recipient places include direct impacts and technology spillovers. Yet in western regions of China, the former results in the narrowed development opportunities of the local enterprises and thus restrain the economic advancement, while the latter may generate positive returns. Other Chinese scholars as Leihui (2006), Gong Xiaoying et al. (2011), Wan Lijuan (2011), Qu Yanlin et al. (2011) conducted their researches from the slightly different perspectives and drew similar conclusions that FDI have promoted the economic development of western regions to some extent.

In recent years, some Chinese scholars with a long list of Zhunian (2007), Gan Erdan (2007), Yang Kesi et al (2007), Li Jihong (2010) sparks their ideas and methodologies in their essays of Chinese versions in the narrowed perspective as exemplified by the Guangxi Zhuang Autonomous Region of China, and their concluding remarks are as similar as that there certainly remain potential gains that have been generated by FDI inflows, and other concerns with the productivity initiatives in social dimensions and the coherent results.

The general literature review discloses that the scholars or practitioners have realized the importance of FDI and certain worries as to the crypto-pressures of FDI in the forms of MNCs may pose on domestic society from the FDI sources and its allotment in the sectors and regions of China, and the hidden environmental problems as well. This essay, based on affirmative data, outlines the panorama of inward FDI flows in Guangxi Zhuang Autonomous Region and aims to formulate corresponding measures to multiply FDI inflows so as to further spur the local economy development.

\section{Portrays of FDI Inflows in Guangxi Zhuang Autonomous Region China}

\subsection{The Limited Scale of FDI Inflows of Guangxi Zhuang Autonomous Region}

Located in the south-west of the coastal areas of China, Guangxi Zhuang Autonomous Region is world renowned for its scenic spots and historic culture, well-endowed with many natural resources, and most importantly, it is the usual and appropriate route of the business connections between China and 10 ASEAN countries. Yet the inward FDI flows in Guangxi is rather limited in scale and marks a huge distance with other developed provinces. 
Table 1. The FDI inflows of Guangxi from the year 1991 to 2010

Measurement Unit: US\$ Million

\begin{tabular}{cccc}
\hline Year & FDI Inflows & Year & FDI Inflows \\
\hline 1991 & 38.71 & 2001 & 384.15 \\
1992 & 180.26 & 2002 & 417.26 \\
1993 & 872.03 & 2003 & 456.19 \\
1994 & 815.06 & 2004 & 295.79 \\
1995 & 669.52 & 2005 & 378.66 \\
1996 & 666.18 & 2006 & 447.40 \\
1997 & 879.86 & 2007 & 683.96 \\
1998 & 886.13 & 2008 & 971.19 \\
1999 & 637.30 & 2009 & 1035.33 \\
2000 & 524.66 & 2010 & 912.00 \\
\hline
\end{tabular}

Data Source: Statistical Yearbook of Guangxi Zhuang Autonomous Region 1992-2011

By almost all accounts, foreign direct investment in Guangxi Zhuang Autonomous Region has been one of the success stories over the past 20 years. Starting from a base of less than US\$40 million in 1991, the stock of FDI in Guangxi ascended to over US\$912 million at the end of 2010. As shown in Table 1, in the chosen time span, the inward FDI flows in Guangxi has created obvious fluctuations and started the real up-soaring trend only since the year 2005, yet the total FDI volume is still in a rather limited scale.

Table 2. The ratio of FDI in Guangxi and the China total from the year 1991 to 2010

Measurement Unit: US\$ Million, percentage \%

\begin{tabular}{lllcrcrcc}
\hline Year & $\begin{array}{l}\text { FDI } \\
\text { Guangxi }\end{array}$ & $\begin{array}{l}\text { FDI in } \\
\text { China }\end{array}$ & $\begin{array}{l}\text { Ratio } \\
\text { Guangxi } \\
\text { and China Total }\end{array}$ & $\begin{array}{r}\text { of } \\
\text { FDI }\end{array}$ & & $\begin{array}{l}\text { FDI } \\
\text { Guangxi }\end{array}$ & $\begin{array}{l}\text { FDI in } \\
\text { China }\end{array}$ & \multicolumn{2}{c}{$\begin{array}{l}\text { Ratio of Guangxi } \\
\text { FDI } \\
\text { and China }\end{array}$} \\
\hline 1991 & 38.71 & 4366 & $0.9 \%$ & 2001 & 384.15 & 46878 & $0.8 \%$ \\
1992 & 180.26 & 11008 & $1.6 \%$ & 2002 & 417.26 & 52743 & $0.8 \%$ \\
1993 & 872.03 & 27515 & $3.2 \%$ & 2003 & 456.19 & 53505 & $0.9 \%$ \\
1994 & 815.06 & 33767 & $2.4 \%$ & 2004 & 295.79 & 60630 & $0.5 \%$ \\
1995 & 669.52 & 37521 & $1.8 \%$ & 2005 & 378.66 & 60325 & $0.6 \%$ \\
1996 & 666.18 & 41726 & $1.6 \%$ & 2006 & 447.40 & 63021 & $0.7 \%$ \\
1997 & 879.86 & 45257 & $1.9 \%$ & 2007 & 683.96 & 74768 & $0.9 \%$ \\
1998 & 886.13 & 45463 & $1.9 \%$ & 2008 & 971.19 & 92395 & $1.1 \%$ \\
1999 & 637.30 & 40319 & $1.6 \%$ & 2009 & 1035.33 & 90033 & $1.1 \%$ \\
2000 & 524.66 & 40715 & $1.3 \%$ & 2010 & 912.00 & 105735 & $0.9 \%$ \\
\hline
\end{tabular}

Data Source: Statistical Yearbook of China 1992-2011, Statistical Yearbook of Guangxi Zhuang Autonomous Region 1992-2011

Ranked by the stock of inward FDI, China has become the leader among all developing nations and second among the APEC nations, only behind the United States in 2000. Then China leaped to the forth host country in 2006 only behind the United States, the United Kingdom and France, afterwards the fifth in 2007 with another forerunner of Canada. In 2009, China is still the world's most attractive investment destination, and ranked the second in absorbing foreign investment, just following the United States. Yet, FDI inflows in Guangxi did not keep in the same pace simultaneously. In the year 1993 and 1994, the inward FDI of Guangxi hit its peak of 3.2\% and 2.4\% respectively in the China total, while in the remaining years the ratio of FDI Guangxi and the total FDI inflows of China is as scarce as only around $1 \%$. 
Table 3. Average yearly growth rate of FDI and other indexes of the sample provinces

Measurement Unit: percentage \%

\begin{tabular}{lccc}
\hline Sample & $\begin{array}{l}\text { Average } \\
\text { Growth Rate of FDI } \\
\text { Provinces }\end{array}$ & $\begin{array}{l}\text { Ratio of FDI in the China } \\
\text { of Year 2005-2010 }\end{array}$ & $\begin{array}{l}\text { Total of the Year 2010 } \\
\text { Rhina of the Year 2010 }\end{array}$ \\
\hline Jiangsu & 16 & 26.95 & 1.5 \\
Guangdong & 11 & 19.16 & 2.98 \\
Fujian & 11 & 9.7 & 4.7 \\
Guangxi & 21 & 0.9 & 0.64 \\
\hline
\end{tabular}

Data Source: Official Statistical Data of the Related Provinces

Table 3 shows how the Guangxi Zhuang Autonomous Region compares with its adjacent neighbors. From the year 2005 till 2010, the average growth rate of inward FDI flows of Guangxi ranks number one as compared with other three provinces. Yet if we keep close eyes only on the unique year 2010, the FDI inflows of Guangxi only took up $0.9 \%$ of the Chinese total, while Jiangsu 26.95\%, Guangdong $19.16 \%$ and Fujian 9.7\%. Meanwhile, the ratio of FDI in the GDP China of the year 2010 appears the huge distance, with Jiangsu 1.5\%, Guangdong 2.98\%, Fujian 4.7\% and Guangxi $0.64 \%$. This is quite self-alleged that FDI inflows of Guangxi is of limited scale, and this will of course overshadow the effects of FDI in the proposed collaborative relationship with the host recipient regions in stimulating the economies as in the ways of promoting market integration, diversifying market supplies, and exercising as strong backbones for the money injections of the economy appetites.

\subsection{The Over-Concentration of FDI Sources}

The main FDI donators of Guangxi Zhuang Autonomous Region are Hongkong China, Macao China, Japan, Singapore, Taiwan China, Thailand, the United States and the British Virgin Islands etc. Along with the establishment of Guangxi ASEAN Free Trade Zone, Guangxi has cultivated close business connections with many south-eastern countries as Malaysia, Indonesia, Laos and Vietnam etc.

Table 4. The main FDI sources of Guangxi from the year 1995 to 2010

Measurement Unit: US\$ Million

\begin{tabular}{llllll}
\hline \multicolumn{1}{c}{ Time } & Year 1995 & Year 2000 & Year 2006 & Year 2009 & Year 2010 \\
Countries & & & & & \\
\hline Hongkong China & 372.26 & 202.04 & 155.59 & 1035.33 & 521.14 \\
Macao China & 24.20 & 13.21 & 4.02 & 18.57 & 25.79 \\
Japan & 31.79 & 5.24 & 10.19 & 4.50 & 13.47 \\
Singapore & 40.39 & 14.07 & 18.17 & 4.29 & 60.10 \\
Taiwan China & 42.95 & 47.50 & 8.80 & 12.00 & 9.90 \\
Thailand & 44.64 & 6.09 & 0.12 & 1.94 & 5.90 \\
The United States & 20.04 & 12.82 & 9.35 & 15.12 & 1.35 \\
The British Virgin & - & 68.15 & 117.04 & 216.66 & 117.08 \\
Islands & & & & & \\
\hline
\end{tabular}

Data Source: Statistical Yearbook of Guangxi Zhuang Autonomous Region 1996-2011

On account of the disaggregated data the year 1995, 2000, 2006, 2009 and 2010, from Table 4 it is extremely obvious that the FDI inflows of Guangxi are overwhelmingly concentrated with Hongkong, Macao and Taiwan as axis powers of FDI injections, while poor contribution from the developed European countries. Hongkong has been the largest source, whilst its dominance is somewhat illusory in that much FDI normally from Hongkong in reality is from elsewhere with some Hongkong-source FDI in China in fact the investment sponsored by domestic Chinese that is round-tripped through Hongkong and others from various western countries. Taiwan, also, has gradually become another doorstep of FDI inflows to China. It is worth to point out the Virgin Islands are part of the UK, thus it predominates an extraordinary key position within the chosen time span. Besides, Thailand, the U.S. and Singapore 
are the core sources of capital injection of China. As disclosed by the official statistics data, in the first three months of the year 2010, in Guangxi Zhuang Autonomous Region, there are 2,388 registered foreign-funded enterprises inclusive of 4,320 branches and subsidiaries, and their FDI climb up to around US\$ 26.10 billion. Among the total flow-in, about $70 \%$ of the capital injection and the enterprises are actually lured up by the overseas Chinese.

The detrimental effect of the dominating overseas stakes is the proneness to monopoly in certain domestic lines, and in this regard the Chinese government should be wary of the finance chaos underlying the capital under-dispersion, if for some certain reasons the withdrawal or shrinkage of the capital backbone may occur deliberately or inadvertently.

\subsection{Lack of Industrial Zoning and Mal-allotment of FDI Inflows}

For quite a long time, the inward FDI in Guangxi clustered in the secondary industry, followed by the tertiary industry, meanwhile the primary industry has hardly been touched. The construction industry and the real estate are the two obvious attractions of FDI inflows.

Table 5. Industry distribution of Guangxi FDI inflows from the year 2000 to 2010

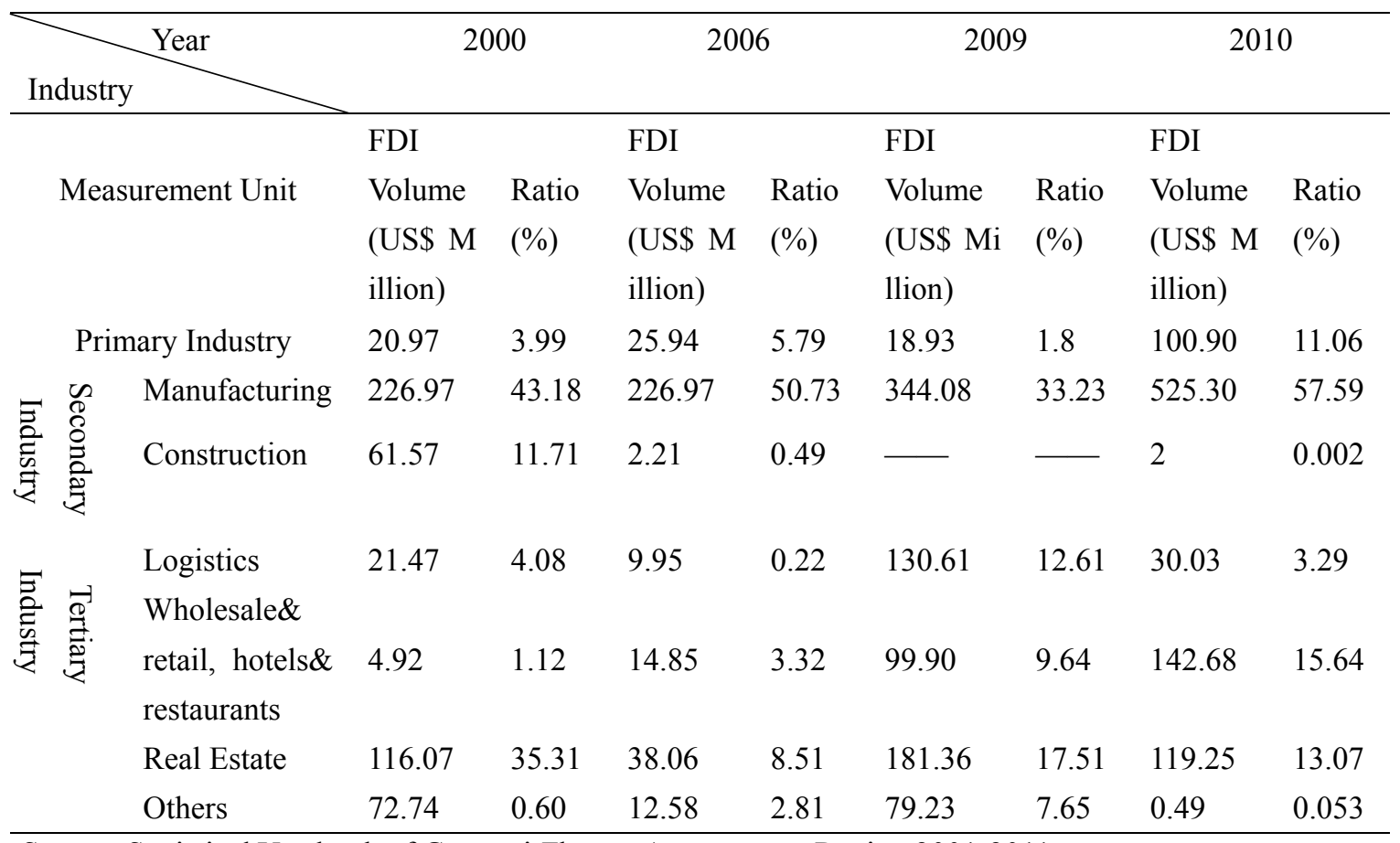

Data Source: Statistical Yearbook of Guangxi Zhuang Autonomous Region 2001-2011

Though we are confined to the missing data of the construction industry in the year of 2009, Table 5 shows that the manufacturing always tops the list of the domestic lines with heavy FDI appetites within the chosen time span. For the ten-year economy development of Guangxi Zhuang Autonomous Region, manufacturing industries remain as the major force in attracting foreign investment. This exemplifies the successful strategy of MNCs that most of them usually locate a fragment of its production activity in the source country. The location of externality-rich economic activities in the recipient regions, as it is exactly the kind of activity that is absolutely being motivated by huge energy and resources inputs. This over-feeding preference with China as exemplified by Guangxi will expedite many new issues as combating pollution, deforestation, preserving ecosystems, plausible exertion of raw materials, and non-point source biological pollution of rivers etc.

As reflected by the Table 5, the FDI proportion of the tertiary industry has fluctuated from time to time, and has climbed up to the peak in 2009 and the paid-in capital stood at US $\$ 411.87$ in total and accounted for $39.76 \%$. The real estate ranks the first in the FDI inflows as shown by the FDI volume and the ratio respectively in the chosen time span. This preference for money donation alleges that profit maximization and cost minimization is the guideline of MNCs choices based on the common sense that service development and real estate in particular is far more fruitful and lucrative. The lack of industrial zoning and mal-allotment of FDI Inflows, of course, will exert negative effects on the economy development of Guangxi Zhuang Autonomous Region, and furthermore on the sustainable development of China economy. 


\subsection{Regions Dislocation of FDI}

The steep gap of FDI dispersion in the eastern, central and western regions of China will definitely be a stimulating force to the economy disequilibrium. For quite a long time, the eastern China is in a high conjunction with the foreign inhabitants, with Guangdong, Jiangsu, Fujian and Shanghai in descending order always the axis powers strengthened by Zhejiang, Beijing, Tianjin and Liaoning. Yet the central and western regions of China are hardly touched by the external fund spurs. This macro trend seems to be strengthened in Guangxi Zhuang Autonomous Region. Nanning, Beihai and Qinzhou are the top three cities to trigger cash inflows, as in the year 2010 the FDI volume amounted to $77.56 \%, 33.08 \%$ and $22.13 \%$ respectively. The optimum geographic location, well-established major infrastructures, the cluster of enterprises and talents employed combine together to build up the advantage and the inflows of FDI consequently have fueled much of the rapid economic growth. The other cities and regions of Guangxi have been less sponsored by the foreign fund. The uneven distribution of the FDI may cement the unbalanced development phase and make the eastern and the western regions of Guangxi polarize in contrasting positions.

\subsection{The Non-diversified Modes of FDI Inflows}

The FDI inflows in Guangxi Zhuang Autonomous Region take the three main modes as sole proprietorship, joint venture and contractual joint venture.

Table 6. The key modes of FDI inflows of Guangxi from the year 1995 to 2010

Measurement Unit: US\$ Million

\begin{tabular}{lrcccc}
\hline $\begin{array}{l}\text { Modes of FDI } \\
\text { Inflows }\end{array}$ & Year 199 & & & Year & \\
\hline Sole & 5 & Year 2000 & Year 2006 & 2009 & Year 2010 \\
Proprietorship & 151.63 & 184.76 & 251.50 & 702.27 & 653.77 \\
Joint Venture & 413.67 & 164.13 & 181.20 & 269.40 & 257.70 \\
Contractual & & & & & \\
Joint Venture & 104.22 & 154.77 & 14.70 & 13.13 & 0.53 \\
\hline
\end{tabular}

Data Source: Statistical Yearbook of Guangxi Zhuang Autonomous Region 2001-2011

As shown in Table 6, in the chosen pinpointed time span, joint venture is the number-one mode in attracting foreign funds in 1995 and accounts for $61.78 \%$ of the total inward FDI flows, while sole proprietorship only took up about $22.64 \%$. From the year 2000, the sole proprietorship became increasingly important and soared up to the percentage of $71.68 \%$. Simultaneously, the contractual joint venture appears in the descending order from 1995 to 2010 . The non-diversified modes of FDI inflows of Guangxi may somewhat constrain the multinational corporations to establish foothold operations and exert impacts on the domestic economy development to some extent.

\section{Conclusions}

Generally speaking, inward FDI acts as a complementary fund source together with domestic investment, which has partly exerted positive powers on economic growth. Yet even within the territory of one nation, the impact of FDI varies among provinces and cities, between industries and regions, depending on resource endowment, geographic location, region characteristics, labor force, and the policy environment as well. Since the FDI spillovers can not, in all probabilities, be easily disentangled from its economic cohesions, the government of Guangxi Zhuang Autonomous Region should conduct the FDI inflows as no more than a cosmetic exercise but strategically tailored to suit the domestic requirements of economic development.

\subsection{Better the Investment Environment and Utilize the Benefits of FDI Inflows}

It is somewhat ominous that much of the foreign furor over foreign-controlled enterprises in China is an offshoot of rich raw materials, comparatively cheap labor force, and the great market potentiality alleged by the huge population. Guangxi Zhuang Autonomous Region, for its world- renowned scenic spots and historic culture, rich natural resources, and most importantly, the doorway of business connections between China and 10 ASEAN countries, is well endowed as FDI incentives for fund injection of multinational companies. The government officials of Guangxi should make the regional investment environment more acceptable to foreign firms from the upstream resource extraction to service delivery and a sound investment climate based on transparent and predictable regulatory and policy framework. The FDI inflows shall spur forward the economic development of Guangxi with the axis power of 
funding the pillar industries as mobile, construction materials and components, sugar, non-ferrous metal etc., and push forward the advantageous industries as foodstuffs, pharmaceutical, hi-tech and so on. Furthermore, it may be expected that the strategically utilized FDI inflows shall definitely support the local firms to move up the global value ladder and try to sink into fertile hi-tech industries.

\subsection{Cultivate Competent Labor Force to Match the Global System}

As is well-known that positive effects of FDI occur only when the host region has a minimum threshold level of proficient human capital, who are highly proficient in technology diffusion, acquisition of product and process innovation, and better management practice. So the government of Guangxi Zhuang Autonomous Region should develop human resources to manage foreign affiliates and operate integrated international production networks. To authorize a wide range of government-funded or organized consortia in research\& development and commercialization of advanced technologies is rather strident. Meanwhile, to give sufficient back support to the local firms to sponsor their R\& D activities is indispensable, thus make innovative use of technologies and further acquiring the core know-hows possible.

\subsection{Enunciate Laws and Regulations}

FDI is a window-dressing if not regulated properly to meet domestic echoes. The legislative members, government officials, enterprise staffs, intelligence communities, and constitution overseers should, in general, be able to find adequate justification in current legislation and regulations to cement the up-soaring trend of the capital inflows, and consequently the multiplying number of affiliates of foreign-funded enterprises. The laws and regulations may announce definitely host or home-nation investment incentives or performance requirements. So, binding procedures to arbitrate the entrance of FDI are requirements of a satisfactory accord. And such fresh procedures should obligate governments as well as international firms with FDI conducts. The implicit and explicit policies and measures should be figured out to under-whelm the characterized take-over of existing enterprises but to orientate more green-field investment. Screening inward investors and planning their business cores combine together to alleviate further environmental problems, and the increasing polarization of the industries, sectors and regions.

\section{References}

Cui, Chenjia, \& Liling. (2010). Research on the Influence of FDI to GDP Growth of Eastern, Mid and Western Regions of China. District Economy, (1), (in Chinese).

Dou, Dengquan. (2011). Empirical Research on the Influence of FDI on the Economic Development of Western Regions of China. Academic Forum, (7), (in Chinese).

Gao, Yanting. (2008). Empirical Research on the Differentiated Influences of FDI on the Economic Development of Eastern and Western Regions of China. Jiangxi Social Science, (7), (in Chinese).

Gong, Xiaoying, \& Cheng Jiawei. (2011). The Empirical Research of Coordinated Spur of FDI Inflows and Economy Development in the Western Regions China-Exemplified by the Guiyang City. The Western Forum, (2), (in Chinese).

Lei, Hui. (2006). Crowing-in Effects of FDI Inflows of Eastern, Mid and Western Regions on the Domestic Investment China-Based on the Panel Data Analysis. China Soft Science, (2), (in Chinese).

$\mathrm{Qu}$, Yanling, \& Shi Benzhi. (2011). Research on the FDI Inflows Dilemma of Western Regions and the Countermeasures. The Ideological Front, (1), (in Chinese).

Wan, Lijuan. (2011). The Underlying Problems and Countermeasures of FDI Trade Effects of Westerns Regions China. Journal of Chongqing University, (5), (in Chinese).

Zhang, Shenling, \& Wu Haiying. (2005). Empirical Research on the Influence of FDI on the Economic Development of Western Regions of China. Social Science in Ningxia, (1), (in Chinese). 